\title{
PENGARUH KEPEMIMPINAN KEPALA UPT PUSKESMAS TERHADAP KINERJA PEGAWAI PUSKESMAS CIAWI KECAMATAN CIAWI KABUPATEN BOGOR
}

\author{
THE IMPACT OF LEADERSHIP ON EMPLOYEES PERFORMANCE AT LOCAL GOVERNMENT \\ CLINIC, CIAWI DISTRICT, BOGOR MUNICIPALITY \\ Irvan Maulana ${ }^{1}$, Rita Rahmawati², Euis Salbiah ${ }^{3}$
}

\begin{abstract}
${ }^{1}$ Jurusan Ilmu Administrasi Negara Fakultas Imu Sosial dan Ilmu Politik Universitas Djuanda, Jl.Tol Ciawi No 1, Kotak Pos 35 Bogor 16770

2 Jurusan Ilmu Administrasi Negara Fakultas Imu Sosial dan Ilmu Politik Universitas Djuanda, Jl.Tol Ciawi No 1, Kotak Pos 35 Bogor 16770

${ }^{3}$ Jurusan Ilmu Administrasi Negara Fakultas Imu Sosial dan Ilmu Politik Universitas Djuanda, Jl.Tol Ciawi No 1, Kotak Pos 35 Bogor 16770
\end{abstract}

(Diterima oleh Dewan Redaksi: 01-02-2017)

(Dipublikasikan oleh Dewan Redaksi: 01-04-2017)

\begin{abstract}
The main objective of this research is to know the impact of leadership and employees performance at Ciawi Local Government Clinic of Bogor Municipality.

Associative method is research method used to know the relationship or impact between two or more variables. The population of this research is 37 employees. To determine the number of minimum sample, Slovin formula is used. Based on the formula, 27 employees taken as sample. To analyze data, Weight Mean Score and Rank Spearman Correlation are used for hypothetical testing purpose. In this context, $\mathrm{H}_{0}: \rho=0$, means that there is no positive correlation between leadership and employees performance, and $\mathrm{H}_{\mathrm{a}}: \rho \neq 0$, means that there is positive correlation between leadership and employees performance.

The result of this research show that leadership function by Head of Local Government Clinic is in "pretty good" criteria with mean score of 2,916 (out of 5) and "pretty good" criteria in all of indicator in this variable. Meanwhile, the variable of employees performance is also categorized as "good" criteria with mean score of 3,000 (out of 5). Futhermore, based on Rank Spearman analysis with significance test for $\mathrm{n}=27$ and standar error of $10 \%$, show that Rho 0,368 with "low" criteria. And the significance test $t=2,042>1,70814$, thus, conclusion can be taken that $\mathrm{H}_{\mathrm{o}}$ is rejected and $\mathrm{H}_{\mathrm{a}}$ is accepted. This mean that there is positive correlation between leadership and employees performance with coefficient of determination $13,5 \%$. In the other words, the research conclusion is the influence of leadership efforts by head of Local Government Clinic is 13,5\% and the remaining $86,5 \%$ is determined by other factors (epsilon).
\end{abstract}

Key word : Leadership, Performance, employees

\begin{abstract}
ABSTRAK
Tujuan utama dari penelitian ini adalah mengetahui pengaruh kepemimpinan Kepala UPT Puskesmas Ciawi dengan kinerja pegawai di Puskesmas Ciawi Kecamatan Ciawi Kabupaten Bogor.

Metode kuantitatif asosiatif adalah metode riset yang digunakan untuk mengetahui hubungan serta pengaruh antara 2 variabel atau lebih. Adapun populasi dari penelitian ini adalah 37 orang pegawai. Untuk menentukan jumlah sampel, digunakan rumus Slovin. Berdasarkan rumus tersebut diambil 27 orang sebagai sampel. Untuk menganalisis data, WMS dan Korelasi Rank Spearman digunakan untuk keperluan uji hipotesis. Dalam hal ini $\mathrm{H}_{0}: \rho=0$, berarti bahwa tidak ada korelasi positif antara kepemimpinan dan kinerja pegawai, dan $\mathrm{H}_{\mathrm{a}}: \rho \neq 0$, berarti bahwa ada korelasi positif antara kepemimpinan dan kinerja.
\end{abstract}


Hasil penelitian menunjukkan bahwa fungsi kepemimpinan yang dilakukan oleh Kepala UPT Puskesmas Ciawi dilaksanakan dengan cukup baik, diperoleh hasil penilaian 2,916 yang menunjukkan kriteria cukup baik dan semua indikator berada dalam posisi cukup baik. Berdasarkan pandangan reponden kinerja pegawai Puskesmas Ciawi sudah berjalan cukup baik dengan nilai 3,000 yang ada pada kriteria cukup baik, dimana 4 indikator berkriteriacukup baik dan 1 indikator berkriteria baik. Pengaruh kepemimpinan terhadap kinerja pegawai di Puskesmas Ciawi, berdasarkan rumus rank spearman dengan taraf kesalahan 10\% harga Rho 0,368 dengan kategori rendah. Dan pada uji signifikansi $\mathrm{t}=2,042>1,70814$, dapat disimpulkan bahwa $\mathrm{H}_{\mathrm{o}}$ ditolak dan terdapat pengaruh positif kepemimpinan terhadap kinerja .Adapun kontribusi positif kepemimpinan terhadap kinerja pegawai (Variabel Y) sebesar 13,5\%. Sedangkan 86,5\% ditentukan oleh faktor lainnya(epsilon).

Kata Kunci : Kepemimpinan, Kinerja, Pegawai

Irvan Maulana, 2017. Pengaruh Kepemimpinan Kepala Upt Puskesmas Terhadap Kinerja Pegawai Puskesmas Ciawi Kecamatan Ciawi Kabupaten Bogor. Jurnal Governansi 


\section{PENDAHULUAN}

Perubahan lingkungan organisasi yang semakin hari semakin kompleks dan kompetitif, menuntut setiap organisasi untuk bersikap cepat tanggap, Proses penyesuaian perubahan organisasi dengan perubahan individu ini sangat tidaklah mudah, karena harus menyatukan banyak pemikiran menjadi satu. agar tetap bertahan dan terus mengembangkan organisasinya.

Untuk mendukung perubahan serta pengembangan organisasi tersebut, maka diperlukan adanya perubahan dari setiap individu baik dari tingkat terendah maupun dari tingkat tertinggi didalam lingkungan organisasi. Dalam hal ini pemimpin sebagai tingkat tertinggi dalam organisasi harus menjadi teladan perubahan kearah yang lebih baik. Oleh karena itu, organisasi membutuhkan pemimpin yang mampu menjadi penggerak serta motivator yang mendorong perubahan serta pengembangan organisasi.

Topik kepemimpinan merupakan topik menarik untuk ditelaah dan diteliti, karena paling sering diamati namun merupakan fenomena yang sedikit dipahami. Dengan demikian tantangan dalam mengembangkan strategi organisasi terletak bukan hanya pada organisasinya, namun juga pada pola kepemimpinan organisasi tersebut.

Pada dasarnya sebuah organisasi atau perusahaan bukan saja mengharapkan pegawai yang mampu, cakap dan terampil, tetapi yang terpenting mereka mau bekerja dengan giat dan berkeinginan untuk mencapai hasil kerja yang maksimal. Kemampuan, kecakapan dan keterampilan pegawai tidak ada artinya, jika mereka tidak mau bekerja keras dengan mempergunakan kemampuan, kecakapan dan keterampilan yang dimilikinya. Oleh karenanya seorang pemimpin harus bisa menumbuhkan kinerja pada pribadi masing-masing pegawainya agar visi misi perusahaan dapat tercapai dengan baik.

Kinerja pegawai berkaitan erat dengan organisai-organisasi pelayanan. Salah satunya adalah organisasi pelayanan dibidang kesehatan. Pada tingkat kecamatan Pusat Kesehatan Masyarakat (Puskesmas) adalah salah satu sarana pelayanan kesehatan masyarakat yang amat penting di Indonesia. Puskesmas adalah unit pelaksana teknis dinas kabupaten/kota yang bertanggung jawab menyelenggarakan pembangunan kesehatan di suatau wilayah kerja (Depkes, 2011).

Puskesmas Ciawi adalah puskesmas yang berada di Kecamatan Ciawi merupakan garda terdepan pemerintah Kecamatan Ciawi dalam pelayanan kesehatan bagi warga masyarakat Kecamatan Ciawi dan bahkan menjadi puskesmas rujukan dari wilayah lain . Hal ini dikarenakan lokasi Puskesmas Ciawi berada di lokasi yang strategis dan mudah dijangkau. Sebenarnya Wilayah kerja puskesmas Ciawi meliputi wilayah Kecamatan Ciawi namun dalam prakteknya banyak pula warga masyarakat dari luar Kecamatan Ciawi yang berobat di Puskesmas Ciawi dan menjadikan rujukan untuk berobat ke rumah sakit umum.

Puskesmas Ciawi Kabupaten Bogor merupakan puskesmas tipe non-Poned. Puskesmas tipe ini adalah puskesmas yang belum memiliki fasilitas atau kemampuan untuk menangani kegawatdaruratan obseteri dan neonatal dasar. Non Poned merupakan kepanjangan dari Pelananan Obsteri Neonatus Essensial dasar. Melihat hal tersebut diperlukan kinerja yang optimal dari setiap pegawai puskesmas baik dari jajaran staff sampai pegawai medis. Kinerja para pegawai harus ditumbuhkan untuk semua pegawai puskesmas, oleh karenanya diperlukan pemimpin yang bisa berperan sebagai motivator bagi para pegawainya.

Berdasarkan informasi dari pegawai puskesmas pada bagian pendaftaran, setiap harinya Puskesmas Ciawi melayani rata-rata sekitar 200 orang pasien, dengan berbagai macam keluhan/penyakit yang diderita. Dari jumlah pasien yang berobat tersebut, hampir sekitar $75 \%$ orang pasien menggunakan BPJS dan sebanyak 20 pasien meminta rujukan untuk berobat ke Rumah Sakit Umum karena tidak bisa ditangani oleh penanganan di Puskesmas.

Berdasarkan hasil pengamatan awal diketahui dampak kurangnya kinerja pegawai UPT Puskesmas Ciawi terlihat dari lamanya proses pelayanan dari mulai pendaftaran, 
pemanggilan pasien, serta menunggu lama untuk mendapatkan obat serta kurang diperhatikannya kebersihan di sekitar puskesmas. Proses pendaftaran yang lamban bisa dikarenakan oleh beberapa faktor seperti kurang tepatnya jam buka dan juga kurang disiplinnya pegawai. Hal tersebut juga dikarenakan banyaknya pasien yang mendaftar pada pagi hari serta kurang koordinasinya antar pegawai sehingga terkadang terjadi missed yang menyebabkan proses pendaftaran yang memerlukan waktu. Dari segi pemanggilan pasien lebih dikarenakan kehadiran dokter atau tenaga medis yang kurang on time sehingga para pasien menunggu lama sekitar 30 - 60 menit rata-rata dari yang sudah dijadwalkan sampai para tenaga medis datang ke Puskesmas.

Sedangkan jika dilihat dari pelayanan pemberian obat, dapat diketahui bahwa untuk mendapatkan obat yang sudah diresepkan oleh tenaga medis, waktu tunggunya pun bisa sekitar 1 - 3 jam. Hal ini dikarenakan kurangnya SDM yang ada pada loket obat dan kurang diperhatikan oleh pihak puskesmas sehingga lama waktu tunggu mulai dari pendaftaran sampai pengambilan obat bisa menyita waktu pasien. Dan juga kebersihan yang kurang diperhatikan oleh petugas kebersihan Puskesmas Ciawi membuat para pasien menjadi kurang nyaman ditambah juga lamanya menunggu antrian seperti yang dijelaskan diatas menjadi pasien kurang mendapatkan pelayanan yang seharusnya diterima.

Berdasarkan hasil pengamatan awal diketahui bahwa permasalahan kurangnya kinerja pegawai di Puskesmas Ciawi diduga karena faktor kepemimpinan yang kurang menjalankan fungsi-fungsi kepemimpinannya dengan maksimal. Jika dilihat dari fungsi-fungsi kepemimpinan yang paling terlihat di Puskesmas Ciawi adalah fungsi pengendalian atau controling terhadap para pegawainya kurang diperhatikan.

Contohnya jarang sekali pegawai yang melanggar mendapatkan teguran walupun sudah ada keluhan yang masuk dari pihak pasien. Hal tersebut berdampak pula pada fungsi instruksi yang terkadang diabaikan oleh pegawai tertentu karena tidak adanya reward and punishment yang diterapkan oleh atasannya.

Dengan demikian dapat dikatakan bahwa sebuah puskesmas memerlukan seorang pemimpin yang mampu menumbuhkan kinerja para pegawainya untuk dapat memberikan kemampuan yang optimal dalam melayani masyarakat. Poinnya adalah pemimpin yang mempunyai rasa optimisme dan pemimpin yang bisa menumbuhkan kinerja pegawainya sangat diperlukan dalam pelaksanaan organisasi puskesmas.

\section{MATERI DAN METODE}

Metode yang digunakan dalam penelitian ini adalah metode deskriptif analisis, dimana Kualitas Pelayanan pegawai ppmkp Dalam Meningkatkan Kepuasaan peserta diklat di Di pusat pelatihan manajamen kepemimpinan dan pertanian digambarkan kemudian dianalisa untuk mendapatkan kesimpilan dari masalah yanga ada. Menurut Hadari Nawawi (2001:63) "Metode deskritif dapat diartikan sebagai prosedur pemecahan masalah yang diselidiki dengan menggambarkan ataua melukiskan keadaan subjek atau objek penelitian (seseorang, lembaga, masyarakat dan lain-lain)

Pada penelitian ini penulis menggunakan dua sampel yaitu sampel pegawai 66 orang dan Peserta diklat33 orang, total sampel dalam penelitian ini berjumlah 99 0rang.

\section{TEKNIK PENGUMPULAN DATA}

Pada penelitian ini penulis menggunakan pendekatan penelitian kuantitatif asosiatif yaitu penelitian yang bertujuan untuk mengetahui pengaruh ataupun juga hubungan antara dua variabel atau lebih. Penelitian ini mempunyai tingkatan tertinggi dibandingkan dengan diskriptif dan komparatif karena dengan penelitian ini dapat dibangun suatu teori yang dapat berfungsi untuk menjelaskan, meramalkan dan mengontrol suatu gejala. Sugiyono, (2013).

Metode penelitian yang penulis gunakan adalah metode penelitian kuantitatif. Zainal 
Arifin (2012:29) Penelitian Kuantitatif adalah penelitian yang digunakan untuk menjawab permasalahan melalui teknik pengukuran yang cermat terhadap variable-variable tertentu, sehingga menghasilkan simpulan-simpulan yang dapat digeneralisasikan, lepas dari konteks waktu dan situasi serta jenis data yang dikumpulkan terutama data kuantitatif.

Untuk memperoleh analisis data dan penarikan kesimpulan maka sampling juga menggunakan perhitungan statistic sederhana yaitu mentransformasikan data kualitatif menjadi kuantitatif, dengan menggunakan perhitungan WMS (Weight Means Scored) yaitu melakukan pembobotan setiap pilihan jawaban. Untuk menafsirkan hasil jawaban dari angket maka dilakukan pembuatan table kriteria penilaian dari hasil angket dengan skala interval sebagai berikut:

$$
\mathrm{i}=\frac{\mathrm{skt}-\mathrm{skr}}{\mathrm{v}}=\underline{5-1}=0.8
$$

Dalam penelitian ini untuk mengetahui hubungan antara gaya kepemimpinan dengan kinerja pegawai Puskesmas Ciawi, peneliti menggunakan rumus korelasi spearman's Rho

Uji korelasi menggunakan korelasi Spearman's Rho (rs) dengan tujuan menguji apakah terdapat hubungan yang signifikan antara variabel bebas dan terikat. Penelitian ini juga ingin melihat pengaruh kepemimpinan terhadap kinerja pegawai, dengan menentukan nilai $R^{2}$ (Koefisien Determinasi). Koefisien determinasi digunakan untuk mengukur seberapa jauh kemampuan model dalam menerangkan variabel-variabel dependen. Nilai koefisien determinasi terletak diantara nol dan satu. Nilai $\mathrm{R}^{2}$ yang kecil berarti kemampuan variabel-variabel independen dalam menjelaskan variasi variabel dependen sangat terbatas. Nilai $\mathrm{R}^{2}$ yang mendekati satu berarti variabelvariabel independen memberikan hampir semua informasi yang dibutuhkan untuk memprediksi variasi variabel dependenn (Suryana, 2009).

\section{Populasi dan Sampel}

Populasi adalah wilayah generalisasi yang terdiri atas objek atau subjek yang mempunyai kualitas dan karakteristik tertentu yang ditetapkan oleh peneliti untuk dipelajari dan kemudian ditarik kesimpulannya. Sugiyono (2007:72)

Sampel adalah sebagian dari populasi yang karakteristiknya dianggap bisa mewakili keseluruhan populasi. Untuk menentukan jumlah sampel yang akan diambil digunakan rumus Slovin (Ginting, 2008:132), yaitu:

$n=\frac{\mathrm{N}}{1+\mathrm{N} e^{2}}$

Maka jumlah sampel yang diperoleh adalah:

$n=\frac{37}{1+37(0,1)^{2}}$

$n=\frac{37}{1+37(0,1)^{2}}$

$n=\frac{37}{1.37}$

$n=27.0072$

Dengan jumlah populasi adalah 37 orang dengan rumus diatas, sampel yang dapat didapat adalah 27,0072 maka jumlah sampel dibulatkan menjadi 27 orang. Dimana semua sampel yang digunakan adalah semua pegawai Puskesmas Ciawi dari mulai tenaga administratif hingga tenaga medis yang presentasenya representatif terhadap penelitian ini.

Tabel.1

Sampel Penelitian

\begin{tabular}{|c|c|c|c|}
\hline $\begin{array}{c}\text { Jenis } \\
\text { Tenaga }\end{array}$ & Populasi & Sampel & Sampel \\
\hline $\begin{array}{l}\text { Dokter } \\
\text { Umum }\end{array}$ & 3 & $\begin{array}{c}(3 / 37) \times 27= \\
2,189\end{array}$ & 2 \\
\hline Dokter Gigi & 1 & $\begin{array}{c}(1 / 37) \times 27= \\
0,729\end{array}$ & 1 \\
\hline $\begin{array}{l}\text { Perawat } \\
\text { Gigi }\end{array}$ & 1 & $\begin{array}{c}(1 / 37) \times 27= \\
0,729\end{array}$ & 1 \\
\hline Bidan & 10 & $\begin{array}{c}(10 / 37) \times 27= \\
7,29\end{array}$ & 7 \\
\hline $\begin{array}{l}\text { Perawat } \\
\text { Umum }\end{array}$ & 6 & $(6 / 37) \times 27=4,37$ & 4 \\
\hline Nutrision & 1 & $\begin{array}{c}(1 / 37) \times 27= \\
0,729\end{array}$ & 1 \\
\hline Kesling & 1 & $\begin{array}{c}(1 / 37) \times 27= \\
0,729\end{array}$ & 1 \\
\hline $\begin{array}{l}\text { Petugas } \\
\text { Farmasi }\end{array}$ & 1 & $\begin{array}{c}(1 / 37) \times 27= \\
0,729\end{array}$ & 1 \\
\hline $\begin{array}{l}\text { Petugas } \\
\text { Analis Lab }\end{array}$ & 1 & $\begin{array}{c}(1 / 37) \times 27= \\
0,729\end{array}$ & 1 \\
\hline $\begin{array}{l}\text { Petugas } \\
\text { Umum }\end{array}$ & 2 & $\begin{array}{c}(2 / 37) \times 27= \\
1,459\end{array}$ & 1 \\
\hline
\end{tabular}




\begin{tabular}{lccc}
\hline Kepala TU & 1 & $\begin{array}{c}(1 / 37) \times 27= \\
0,729 \\
(1 / 37) \times 27= \\
0,729\end{array}$ & 1 \\
$\begin{array}{l}\text { Administra } \\
\text { si }\end{array}$ & 1 & $\begin{array}{c}(3 / 37) \times 27= \\
2,189 \\
\begin{array}{l}3 / 37) \times 27= \\
2,189\end{array}\end{array}$ & 2 \\
$\begin{array}{l}\text { Pendaftara } \\
\text { Petugas }\end{array}$ & 3 & $\begin{array}{c}2 / 37) \times 27= \\
1,459\end{array}$ & 1 \\
$\begin{array}{l}\text { Kebersihan } \\
\text { Petugas }\end{array}$ & 3 & 0 & 0 \\
$\begin{array}{l}\text { Loket Obat } \\
\text { Petugas } \\
\text { Keamanan }\end{array}$ & 2 & & $\mathbf{2 7}$ \\
\hline & 0 & &
\end{tabular}

\section{Teknik Pengumpulan Data}

Untuk mendapatkan data yang relevan dan sesuai dengan kebutuhan yang berkaitan dengan penelitian, maka teknik pengumpulan data yang digunakan dalam penelitian ini, sebagai berikut:

1. Penyebaran Angket, dilakukan untuk memperoleh data primer dengan cara membuat daftar pernyataan yang diberikan secara tertulis kepada responden penelitian yaitu pegawai pada Puskesmas Ciawi yang dipilih sebagai sampel penelitian

2. Studi lapangan, yaitu dilakukan langsung ke lapangan guna mendapatkan data melalui Studi kepustakaan dan dokumentasi, yaitu pengumpulan data dengan cara mengumpulkan bahan-bahan tertulis berupa literatur, media masa, data statistik dan studi dokumentasi untuk memperoleh konsep teoretik dari masalah penelitian.

\section{Teknik Analisis Data}

Menganalisa data yang terkumpul peneliti menggunakan metode statistik. Karena jenis penelitian yang digunakan adalah penelitian kuantitatif. Untuk menyederhanakan data dalam bentuk yang lebih mudah dibaca dan diinterpretasikan.

Setiap jawaban dari angket kepemimpinan dan kinerja dilakukan dengan memberikan bobot atau skor yang disusun secara bertingkat berdasarkan skala likert. Pemberian skor dilakukan pada setiap jawaban angket kepemimpinan dan kinerjayang telah dijawab sampel penelitian dengan bentuk jawaban dan bobot/skor seperti yang dikemukakan pada tabel dibawah.
Tabel.2

Kriteria bobot/skor

\begin{tabular}{ccc}
\hline Bentuk Jawaban & Simbol & Bobot / Skor \\
Sangat Tidak Setuju & STS & 1 \\
Tidak Setuju & TS & 2 \\
Cukup Setuju & CS & 3 \\
Setuju & S & 4 \\
Sangat Setuju & SS & 5 \\
\hline
\end{tabular}

Perolehan angka penafsiran WMS sebagai berikut:

$$
\sum M=\frac{f(x)}{N}
$$

Keterangan:

$\mathrm{M}=$ perolehan angka penafsiran

$\mathrm{F} \quad=$ Pembobotan skala nilai

$\Sigma \quad=$ Jumlah

$\mathrm{N} \quad=$ Jumlah sampel penelitian

Pemberian score menurut seperti ini akan mendapatkan variasi jawaban yang bergerak dari 1 sampai 5 sehingga diperoleh interval antara 1 dengan yang lain yaitu 0,80. Sehingga diperoleh kriteria penafsiran sebagai berikut:

Tabel.3

Kriteria Penafsiran

\begin{tabular}{cl}
\hline Interval Score & \multicolumn{1}{c}{ Kriteria } \\
$4,21-5,00$ & Sangat Baik \\
$3,41-4,20$ & Baik \\
$2,61-3,40$ & Cukup Baik \\
$1,81-2,60$ & Kurang Baik \\
$1,00-1,80$ & Sangat Tidak Baik \\
\hline
\end{tabular}

Dalam rangka menguji hipotesis maka digunakan rumus Rank Spearman :

$$
r_{s}=1-\frac{6 \sum d_{i}^{2}}{n\left(n^{2}-1\right)}
$$

Keterangan:

$\mathrm{r}_{\mathrm{s}}=$ Koefisien Korelasi rank

$\mathrm{d}=\operatorname{rank} \mathrm{X}-\operatorname{rank} \mathrm{Y}$

$\mathrm{n}=$ Sampel

Untuk dapat memberikan penafsiran terhadap koefisien korelasi yang ditemukan tersebut besar atau kecil maka dapat berpedoman pada sugiyono (2013: 184) 
Tabel. 4

Interpretasi Koefisien Korelsi

\begin{tabular}{cc}
\hline $\begin{array}{c}\text { Interval } \\
\text { Koefisien }\end{array}$ & $\begin{array}{c}\text { Tingkat } \\
\text { Hubungan } \\
\text { Sangat Renda }\end{array}$ \\
& $\mathrm{h}$ \\
$0,000-0,199$ & Rendah \\
$0,400-0,399$ & Sedang \\
$0,600-0,799$ & Kuat \\
$0,800-0,999$ & Sangat Kuat \\
\hline
\end{tabular}

Untuk menguji keberartian koefisien korelasi antara variabel X dan Y dilakukan dengan membandingkan $t_{\text {hitung }}$ dengan $t_{\text {tabel }}$ yaitu dengan menggunakan rumus distribusi student (tstudent). (Thoifah, 2015: 223)

Keterangan:

$$
t=r s \frac{\sqrt{n-2}}{1-r s 2}
$$

$\mathrm{t}=$ distribusi student

rs $=$ koefisien korelasi rank

Setelah thitung diketahui dan didapatkan, dilakukan pembandingan $t_{\text {hitung }}$ dengan $t_{\text {tabel }}$ dengan penafsiran sebagai berikut :

Jika $\mathrm{t}_{\text {hitung }}<\mathrm{t}_{\text {tabel}}$, maka $\mathrm{H}_{0}$ diterima, artinya tidak ada pengaruh yang signifikan antara kepemimpinan dengan kinerja pegawai.

Jika $t_{\text {hitung }}>t_{\text {tabel }}$, maka $H_{0}$ ditolak, artinya ada pengaruh yang signifikan antara kepemimpinan dengan kinerja pegawai.

\section{HASIL DAN PEMBAHASAN}

Berdasarkan hasil penelitian, pelaksanaan kepemimpinan Kepala UPT Puskesmas Ciawi termasuk kriteria cukup baik dengan hasil penafsiran 2,916. Dengan demikian dapat disimpulkan bahwa berdasarkan pendapat responden pelaksanaan kepemimpinan sudah cukup baik.

Namun demikian semua indikator fungsi kepemimpinan Kepala UPT Puskesmas Ciawi harus ditingkatkan, khususnya pada fungsi instruksi, konsultasi serta fungsi pengendalian yang nilainya kurang dari 3,000. Dengan data diatas pimpinan harus melakukan evaluasi untuk perbaikan fungsi-fungsi kepemimpinan, agar tercapai visi misi organisasi dengan cepat dan akurat.
Tabel.5

Rekapitulasi Variabel (x) Kepemimpinan

\begin{tabular}{lll}
\hline $\begin{array}{l}\text { Indikator } \\
\text { Fungsi }\end{array}$ & $\begin{array}{l}\text { Hasil } \\
\text { Penilaian }\end{array}$ & $\begin{array}{l}\text { Hasil } \\
\text { Penafsiran }\end{array}$ \\
$\begin{array}{l}\text { Fungsi } \\
\text { konsultasi. }\end{array}$ & 2,855 & Cukup Baik \\
$\begin{array}{l}\text { Fungsi } \\
\text { partisipasi. }\end{array}$ & 3,0055 & Cukup Baik \\
$\begin{array}{l}\text { Fungsi } \\
\text { delegasi. }\end{array}$ & 3,260 & Cukup Baik \\
$\begin{array}{l}\text { Fungsi } \\
\text { controling. }\end{array}$ & 2,610 & Cukup Baik \\
& $14,58 / 5=$ & Cukup Baik \\
& 2,916 & Cukup Baik \\
\hline
\end{tabular}

Tabel.5

Rekapitulasi Variabel (y) Kinerja Pegawai

\begin{tabular}{lll}
\hline $\begin{array}{l}\text { Indikator } \\
\text { Kualitas }\end{array}$ & $\begin{array}{l}\text { Hasil } \\
\text { Penilaian }\end{array}$ & $\begin{array}{l}\text { Hasil } \\
\text { Penafsiran }\end{array}$ \\
$\begin{array}{l}\text { Ketetepan } \\
\text { Kerja }\end{array}$ & 3,035 & Cukup Baik \\
Inisiatif & 3,280 & Cukup Baik \\
Kemampuan & 2,965 & Cukup Baik \\
Komunikasi & 2,945 & Cukup Baik \\
& $15 / 5=$ & Cukup Baik \\
& 3,000 & Cukup Baik \\
\hline
\end{tabular}

Berdasarkan hasil penelitian, pelaksanaan kinerja pegawai Puskesmas Ciawi termasuk kriteria cukup baik dengan hasil penafsiran 3,000. Dengan demikian dapat disimpulkan bahwa berdasarkan pendapat responden pelaksanaan kepemimpinan sudah cukup baik. Namun untuk hasil yang harus ditingkatkan khususnya pada indikator kemampuan karena berkaitan erat dengan profesi sebagai tenaga medis dan pelayanan kesehatan dan komunikasi pegawai baik secara vertikal maupun horizontal agar pekerjaan menjadi mudah dan tidak ada jarak lagi antara pemimpin dan pegawainya.lebih baik dikemudian hari, baiknya setiap indikator kinerja pegawai.

Mencari Koefisien Korelasi sederhana (rank spearman)

$\mathrm{rs}=1-\frac{6 \sum d^{2}}{n\left(n^{2}-1\right)}$ 
$\mathrm{rs}=1-\frac{6(2070,5)}{27\left(27^{2}-1\right)}$

$\mathrm{rs}=1-\frac{12423}{27(729-1)}$

$\mathrm{rs}=1-\frac{12423}{19656}$

rs $=0,368$

Berdasarkan hasil perhitungan dengan rumus Rank Spearman didapatkan hasil 0,368 dengan hasil penafsiran Rendah berdasarkan sugiyono (2013:184). Dengan demikian tingkat hubungan antara variable kepemimpinan dengan variable kinerja pegawai di Puskesmas Ciawi Kecamatan Ciawi memiliki hubungan yang rendah.

$$
\begin{aligned}
& t=r s \frac{\sqrt{n-2}}{1-r s 2} \\
& t=0,368 \frac{\sqrt{27-2}}{1-(0,368) 2} \\
& t=0,368 \frac{\sqrt{25}}{1-0,135} \\
& t=0,368 \frac{\sqrt{25}}{1-0,135} \\
& t=0,368 \frac{\sqrt{25}}{0,865} \\
& t=0,368 \times \sqrt{28,9} \\
& t=0,368 \times 5,376 \\
& \boldsymbol{t}
\end{aligned}
$$$$
\text { Selanjutnya Mencari Signifikansi }
$$$$
\text { Korelasi Sederhana (Rank Spearman) }
$$

Hal ini dapat digambarkan sebagai berikut:

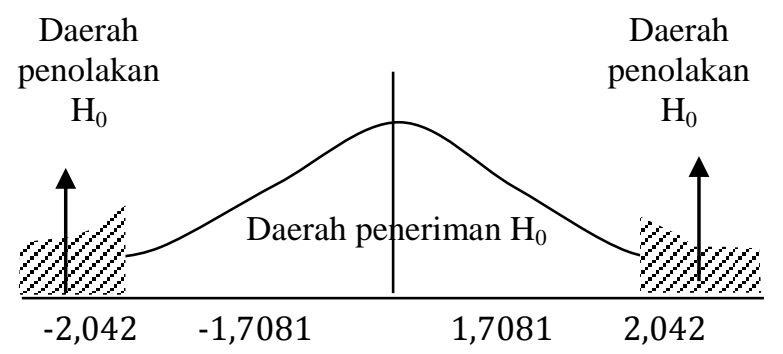

Gambar 1.1.

kurva normal dalam pengujian hipotesis penelitian

Berdasarkan hasil perhitungan dengan rumus Uji Signifikasi (Uji-t) diatas didapatkan $t_{\text {hitung }} 2,042$. Berdasarkan Tabel distribusi dengan taraf kesalahan 10\% adalah 1.70814. Karena $\mathrm{T}_{\text {hitung }}>\mathrm{T}_{\text {tabel }}$ $(2,042>1,70814)$. Dengan hasil tersebut bahwa hipotesis penelitian $\mathrm{H}_{0}$ ditolak, dan alternatif hipotesis $\mathrm{H}_{\mathrm{a}}$ diterima karena terdapat pengaruh kepemimpinan terhadap kinerja pegawai di Puskesmas Ciawi.

Selanjutnya adalah mengetahui nilai koefisien determinasi variabel $\mathrm{X}$ terhadap variabel $\mathrm{Y}$, maka penulis lakukan proses penghitungan dengan rumus :

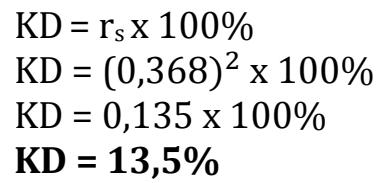

Berdasarkan hasil perhitungan Korelasi Sederhana dengan menggunakan rumus Rank Spearman dihasilkan bahwa pengaruh kepemimpinan Kepala UPT Puskesmas Ciawi terhadap kinerja Pegawai Puskesmas Ciawi adalah $13,5 \%$ dan sisanya $86,5 \%$ dipengaruhi oleh faktor diluar variable kepemimpinan. Dengan data tersebut bahwa kepemimpinan Kepala Puskesmas Ciawi mempengaruhi kinerja pegawai Puskesmas Ciawi sebanyak $13,5 \%$.

Walaupun dalam hasil penelitian ini, bahwa pengaruh kepemimpinan terhadap kinerja pegawai di Puskesmas Ciawi relatif rendah. Namun demikian, hasil penelitian ni membuktikan bahwa kepemimpinan merupakan salah satu faktor yang mempengaruhi kinerja pegawai baik dalam organisasi privat maupun bagi organisasi publik. Khususnya dalam bidang pelayanan kesehatan kepada masyarakat.

\section{KESIMPULAN DAN IMPLIKASI}

1. Pelaksanaan kepemimpinan Kelapa UPT Puskesmas Ciawi dilaksanakan dengan cukup baik, dengan hasil 2,916 yang menunjukkan kriteria cukup baik. Dan semua indikator pada posisi cukup baik. 
2. Pelaksanaan kinerja pegawai Puskesmas Ciawi dilaksanakan dengan cukup baik, dengan hasil 3,000 yang menunjukkan kriteria cukup baik. Dari 4 indikator pada posisi cukup baik dan 1 indikator pada posisi baik.

3. Berdasarkan hasil perhitungan dengan rumus Rank Spearman didapatkan hasil 0,368 dengan hasil penafsiran Rendah Berdasarkan hasil perhitungan dengan rumus Uji Signifikasi (Uji-t) diatas didapatkan $t_{\text {hitung }}$ 2,042. Berdasarkan Tabel distribusi dengan taraf kesalahan 10\% adalah 1.70814. Karena $\mathrm{T}_{\text {hitung }}>\mathrm{T}_{\text {tabel }}(2,042$ $>1,70814$ ), maka $\mathrm{H}_{0}$ ditolak.

Pengaruh Kepemimpinan terhadap Kinerja Pegawai Puskesmas Ciawi sebesar $13,5 \%$ dan $86,5 \%$ ditentukan oleh faktor lainnya.

\section{DAFTAR PUSTAKA}

A.A. Anwar Prabu Mangkunegara. 2005. Evaluasi Kinerja Sumber Daya Manusia. Bandung : Refika Aditama

Alex, S.,Nitisemito. 2001. Manajemen Personalia: Manajemen Sumber Daya Manusia. Jakarta : Ghalia Indonesia

Arifin, Zaenal, 2012. Evaluasi Pembelajaran. Bandung : PT. Remaja Rosdakarya

Darwin, Sudarwan, 2012. Kepemimpinan Pendidikan (Kepemimpinan Jenius $I Q+E Q$, Etika, Perilaku Motivasional, dan Mitos).Bandung: Alfabeta

Departemen Agama RI, 2010. Al-Hikmah AlQur'an dan Terjemahnya. Bandung: Diponegoro

Departmen Kesehatan. 2011. Sistem Kesehatan. Jakarta.

Departmen Kesehatan. 2007. Direktorat Jendral Bina pelayanan Medik Standar Minimal Pelayanan Kesehatan Gigi Puskesmas.

Gibson, et.al. 1995. Organisasi dan Manajemen, Edsi Keempat. Jakarta : Erlangga

Goleman. 2003. Kepemipinan yang Mendatangkan Hasil, Cetakan Pertama. Yogyakarta : Amora Books

Gunawan, Heri. 2012. Pendidikan Karakter Konsep dan Implementasi, Bandung: Alfabeta.

Hasibuan, Malayu S.P. 2006. Manajemen Dasar, Pengertian dan Masalah.Edisi Revisi. Jakarta: Bumi Aksara.

Hasibuan, Malayu S.P. 2010. Organisasi dan Motivasi: Dasar Peningkatan
Produktivitas. Cetakan Ketujuh. Jakarta: Bumi Aksara.

Hasibuan, Malayu S.P. 2013. Manajemen Sumber Daya Manusia. Cetakan Pertama. Jakarta: Bumi Aksara.

Kartono, Kartini.2003. Pemimpin dan Kepemimpinan : Apakah Pemimpinan

Abnormal Itu ? PT Raja Grafindo Persada, Jakarta.

Mathis, Robert L.,Jackson, John H. 2006. Manajemen Sumber Daya Manusia. Jakarta : Salemba Empat

Mulyasa, 2012. Manajemen Berbasis Sekolah. Bandung: PT Remaja Rosdakarya

Nawawi, Hadari.2006. Kepemimpinan Mengefektifkan Organisasi. Yogyakarta : Gajah Mada University Press

Neviyarni, 2009. Pelayanan Bimbingan dan Konseling Berorientasi Khalifah Fil Ardh. Bandung: Alfabeta

Schermerhorn, John R. 2010 Introduction to Management. Asia: Permission

Departement,

Sedarmayanti. 2007. Sumber Daya Manusia dan Produktivitas Kerja. Bandung : Mandar Maju

Simamora, Henry. 20606. Manajemen Sumber Daya Manusia. Yogyakarta : STIE YKPN

Sugiyono, 2006. Metode Penelitian Pendidikan Pendekatan Kuantitatif, kualitatif, dan $R \& D$, Bandung: Alfabeta, 2006, cet. Ke-2

Suharsimi Arikunto, 2006. Prosedur Penelitian; Suatu Pendekatan Praktik, Jakarta: PT. Rineka Cipta, 2006

Thoha, Miftah. 2003. Perilaku Organisasi Konsep Dasar dan Aplikasinya. Jakarta: PT. Raja Grafindo Persada

Thoha, Miftah. 2012. Kepemimpinan dalam Manajemen. Jakarta: PT. Raja Grafindo Persada.

Thoifah, I'anatut. 2015. Statistika Pendidikan dan Metode Penelitian Kuantitatif. Jawa Timur : Madani

Veithzal, Rivai. 2008. Kepemimpinan dan Perilaku Organisasi. Jakarta: PT. Raja Grafindo Persada.

Veithzal, Rivai dan Sagala, Ella Jauvani. 2009. Manajemen Sumber Daya Manusia untuk Perusahaan: Dari Teori ke Praktik. Jakarta: PT. Raja Grafindo Persada.

Wagimo, Hubungan Kepemimpinan Transformasional dan Transaksional dengan Motivasi Bawahan di Militer, 
Jurnal Psikologi, Vol. 32, No. 2, HIm. 116-117, Di unduh tanggal 02 September 2016 pukul 21.34 WIB

Wahjosumidjo. 1992. Kepemimpinan dan Motivasi. Jakarta : Ghalia Indonesia

Wahjosumidjo. 1992. Kepemimpinan Kepala Sekolah Tinjauan Teoritik dan Permaslahannya. Jakarta : PT. Raja Grafindo Persada

Wibowo. 2007. Manajemen Kinerja. Jakarta :

PT. Rajagrafindo Persada 